\title{
Seleção de isolados de Metarhizium anisopliae (Metsch.) Sorok. a Mahanarva fimbriolata (Stal, 1854) (Hemiptera: Cercopidae)
}

\section{Screening of Metarhizium anisopliae (Metsch.) Sorok. strains against Mahanarva fimbriolata (Stal, 1854) (Hemiptera: Cercopidae)}

\author{
Daniella Macedo ${ }^{1 *}$; Sérgio Batist Alves ${ }^{2}$; Solange Aparecida Vieira ${ }^{3}$
}

\section{Resumo}

\begin{abstract}
A colheita mecanizada de cana-de-açúcar, sem a queima da palhada, proporciona acúmulo de matériaorgânica no solo tornando o ambiente favorável ao desenvolvimento da cigarrinha-da-raiz, Mahanarva fimbriolata (Stal, 1854) (Hemiptera: Cercopidae). Em elevadas infestações essa praga tem causado prejuízos devido aos grandes danos nas plantas e aos gastos com agrotóxicos. O objetivo da pesquisa foi selecionar isolados de Metarhizium anisopliae (Metsch.) Sorok. patogênicos para cigarrinha-da-raiz, usando uma nova metodologia. A seleção foi feita em condições de laboratório, utilizando-se ninfas coletadas a campo que foram pulverizadas com o fungo e mantidas em raiz de mudas de cana-de-açúcar. A mortalidade corrigida ao quinto dia após a inoculação variou de 10,5 a $60 \%$, sendo que os isolados mais patogênicos causaram mortalidades de 46,5 a 59,7\%.
\end{abstract}

Palavras-chave: Cigarrinha-da-raiz, fungo entomopatogênico, controle microbiano, cana-de-açúcar

\begin{abstract}
The mechanized harvest of sugarcane results in accumulation of mulch on the soil and promotes favorable temperature and moist to development of sugarcane root spittlebug, Mahanarva fimbriolata (Stal, 1854) (Hemiptera: Cercopidae). High populations of this pest causes serious damages to plants and high costs with insecticides. This research work tested strains of Metarhizium anisopliae (Metsch.) Sorok. pathogenic to sugarcane root spittlebug using a new methodology. The selection was carried out in laboratory conditions. Nymphs were sprayed with $2 \mathrm{~mL}$ of a suspension containing $5 \times 10^{7}$ conidia $/ \mathrm{mL}$ and maintained in roots of sugarcane. The corrected mortality was evaluated five days after pulverization and ranged from 10.5 to $60 \%$ and the more pathogenic strains caused mortality from 46.5 to $59.7 \%$.

Key words: Root spittlebug, entomopathogenic fungi, microbial control, sugarcane
\end{abstract}

1 Doutora em Entomologia pela Escola Superior de Agricultura “Luiz de Queiroz" (ESALQ-USP). Email:danimacedo05@yahoo.com.br

2 Professor Titular do Departamento de Entomologia, Fitopatologia e Zoologia Agrícola da Escola Superior de Agricultura "Luiz de Queiroz" (ESALQ-USP), Piracicaba-SP

3 Bióloga formada pela Universidade Metodista de Piracicaba (UNIMEP)

* Autor para correspondência. 
A cultura da cana-de-açúcar ocupa cerca de 5,57 milhões de hectares de área colhida no Brasil. Apesar da grande importância da cultura para o país, parte da produção ainda é perdida devido aos danos causados por várias pragas, dentre as quais, as cigarrinhas pertencentes ao gênero Mahanarva. A cigarrinha-da-raiz, Mahanarva fimbriolata (STAL, 1854) (Hemiptera: Cercopidae), era considerada de importância econômica somente em algumas plantações do Nordeste, onde causava perdas de 30 a $60 \%$ da produção nos Estados de Sergipe e Bahia, respectivamente (MENDONÇA; BARBOSA; MARQUES, 1996). Recentemente, com o aumento das áreas de colheita mecanizada de cana "crua", no Estado de São Paulo, as infestações de $M$. fimbriolata tornaram-se mais elevadas, constituindose atualmente em um dos mais preocupantes problemas para a cultura, especialmente em locais de temperatura elevada e alta umidade proporcionada pela abundante cobertura vegetal deixada no solo (MACEDO et al., 1997; DINARDOMIRANDA; COELHO; FERREIRA, 2004). Os seus danos podem ser classificados em diretos e indiretos. Os primeiros caracterizam-se pela morte, encurtamento, rachadura, brotações laterais e murchamento de colmos e redução na produtividade (tonelada de cana/ha) causada por morte precoce de perfilhos. Já os indiretos, pela redução da quantidade e qualidade do açúcar recuperável causada por aumento no teor de fibra, aumento de impurezas (trash), redução da porcentagem de Pol do caldo da cana (PCC), redução na pureza do caldo e aumento de contaminantes no caldo (DINARDOMIRANDA; COELHO; FERREIRA, 2004; MACEDO; MACEDO, 2004). As áreas com maiores infestações possuem aspecto de canavial queimado, com as folhas superiores apresentando estrias amareladas, pardas ou necrosada, além de grande quantidade de espuma ao redor das touceiras (AZZI; DODSON, 1971).

Atualmente a maioria das variedades cultivadas é susceptível à praga, causando reduções de produtividade em decorrência de seu ataque. Os métodos de controle mais utilizados são o químico, com a aplicação de inseticidas e o biológico, principalmente o microbiano, com o fungo $M$. anisopliae, que é de ocorrência natural em muitas áreas e vem sendo produzido em laboratório e aplicado a campo com resultados promissores em algumas regiões. Deve-se lembrar que o objetivo do controle microbiano, como em qualquer programa de controle biológico, não deve ser a total eliminação da população da praga, pois, sendo ela um componente do agroecossistema, sua presença, em níveis abaixo do nível de dano econômico, pode ser benéfica para a manutenção de outras pragas potenciais abaixo do nível de dano econômico, dos predadores, parasitóides e patógenos já presentes na área (SOSA-GÓMEZ; PEREIRA; ALVES, 1998).

A utilização dessa tecnologia para o controle de M. fimbriolata tem sido testada e utilizada há muito tempo e é extremamente interessante por razões ambientais e econômicas. Freire, Souto e Marques (1968) fizeram levantamentos sobre os principais inimigos naturais de cigarrinhas da cana-de-açúcar e constataram a importância e potencial do fungo M. anisopliae. Macedo et al. (1977) avaliaram o fungo $M$. anisopliae para o controle de cigarrinhada-raiz como alternativa para o controle químico e por ser um agente de controle de ocorrência natural.

Muitos estudos têm sido feitos com o objetivo de avaliar a utilização de $M$. anisopliae como método de controle, principalmente em áreas em que o fungo ocorre naturalmente. Porém, nem sempre o isolado encontrado na área é o mais indicado para a produção e aplicação massal.

Dessa maneira, o objetivo da pesquisa foi selecionar isolados de $M$. anisopliae patogênicos para a cigarrinha-da-raiz, M. fimbriolata.

O experimento foi realizado no Laboratório de Patologia e Controle Microbiano de Insetos do Setor de Entomologia da ESALQ-USP, utilizando-se 20 isolados de $M$. anisopliae e ninfas de $M$. fimbriolata. O delineamento foi inteiramente casualizado com 30 insetos por tratamento, divididos 
em 10 repetições (3 ninfas/repetição). Dos 20 isolados de $M$. anisopliae testados, onze encontramse armazenados em freezer $\left(-12^{\circ} \mathrm{C}\right)$ na forma de conídios puros, sob óleo mineral e/ou liofilizados no Banco de Patógenos do referido laboratório. Os outros nove isolados foram fornecidos pelo Laboratório de Controle Biológico do Instituto Biológico de Campinas (IBCB). Dezoito isolados testados foram obtidos de cigarrinhas (M. fimbriolata e M. posticata), um de Diatraea saccharalis (ESALQ 935), e o isolado padrão (ESALQ 1037) foi obtido de Solenopsis sp.

As ninfas de $M$. fimbriolata foram coletadas, com o auxílio de uma colher, em área de cultivo comercial de cana-de-açúcar, onde se faz a colheita de "cana crua", sem nenhum tratamento para o controle da praga (Usina São João, localizada no município de Araras - SP). Após a coleta, as ninfas foram acondicionadas em caixas plásticas $(37$ x 25 x $11 \mathrm{~cm}$ ) contendo folhas de cana-de-açúcar e levadas ao laboratório onde, no dia seguinte, foram separadas por tamanho (de 5 a $7 \mathrm{~mm}$ de comprimento) em grupos de 30 , os quais foram pulverizados com os respectivos tratamentos.

Conídios dos isolados foram transferidos para placas de Petri esterilizadas contendo meio de cultura completo (MC) $(0,36 \mathrm{~g}$ de fosfato de potássio; $1,05 \mathrm{~g}$ de fosfato de sódio; $0,6 \mathrm{~g}$ de sulfato de magnésio; $1,0 \mathrm{~g}$ de cloreto de potássio; $10 \mathrm{~g}$ de glucose; $1,58 \mathrm{~g}$ de nitrato de sódio; $5,0 \mathrm{~g}$ de extrato de levedura; $20 \mathrm{~g}$ de ágar; $1000 \mathrm{~mL}$ de água destilada) previamente autoclavado a $120^{\circ} \mathrm{C}$ por 20 minutos, e foram espalhados com o auxílio de alça de Drigalski. Após a inoculação, as placas foram mantidas em câmara climatizada a $26 \pm 0,5^{\circ} \mathrm{C} ; 80 \pm 5 \% \mathrm{UR} ; 12$ horas de fotofase durante um período de dez dias para crescimento e esporulação do fungo.

Decorridos dez dias, os conídios foram retirados das placas, com o auxílio de uma espátula, e transferidos para tubos de dieta contendo $10 \mathrm{~mL}$ de água destilada estéril mais espalhante adesivo a $0,01 \%$ (Tween $40^{\circledR}$ ). Foram feitas três diluições em série, sendo a terceira utilizada para a contagem dos conídios em câmara de Neubauer. Após esse procedimento, uma suspensão de concentração de 5 x $10^{7}$ conídios por mililitro foi preparada, a partir da suspensão original, para ser pulverizada. Essa concentração foi selecionada em função de testes de patogenicidade realizados pelo Instituto Biológico de Campinas (Almeida, comunicação pessoal).

Cada isolado (tratamento) foi inoculado, por pulverização, em 30 ninfas de M. fimbriolata em uma placa de Petri de $14 \mathrm{~cm}$ de diâmetro. A pulverização foi realizada em Torre de Potter (Burkard Manufacturing Rickmansworth, Herts, Reino Unido) calibrada a 15 libras/pol ${ }^{2}$, utilizando-se dois mililitros da suspensão de conídios, correspondendo a $0,2 \mathrm{~mL} / \mathrm{cm}^{2}$. O tratamento Testemunha foi pulverizado com água destilada estéril mais espalhante adesivo a $0,01 \%$ (Tween $40^{\circledR}$ ).

Após a pulverização, os insetos foram transferidos para as raízes das mudas de cana-de-açúcar, perfazendo três ninfas/planta e dez plantas por tratamento. As mudas foram obtidas no Centro de Ciências Agrárias da Universidade Federal de São Carlos (CCA-UFSCar) em Araras-SP e vieram acondicionadas em copos plásticos os quais tiveram o fundo recortado para expor as raízes onde foram colocadas as ninfas já pulverizadas. Para individualizar as mudas cada copo, contendo uma muda, foi colocado sobre o fundo de uma placa de Petri ( $9 \mathrm{~cm}$ de diâmetro) e cada tratamento foi individualizado em bandejas plásticas. Estas mudas, molhadas diariamente com água destilada, foram mantidas em sala com fotofase de $12 \mathrm{~h}$ a $27 \pm 1^{\circ} \mathrm{C}$ durante todo o período de avaliação. As avaliações de mortalidade foram realizadas no quinto dia após a inoculação, sendo realizadas observações diárias, para coleta dos adultos que emergiam.

A seleção de isolados foi baseada na porcentagem de mortalidade de $M$. fimbriolata no período de avaliação, determinando-se assim a patogenicidade de cada isolado para o inseto. Os isolados selecionados foram aqueles que apresentaram maior mortalidade, corrigida pela da fórmula de Schneider- 
Orelli (Mortalidade corrigida $=[(\%$ de mortalidade no tratamento - \%mortalidade na testemunha)/(100 - \%mortalidade na testemunha)*100]), cinco dias após a inoculação.

Todos os isolados foram patogênicos para a $M$. fimbriolata. As mortalidades corrigidas das ninfas variaram de 10,5 a 60\%, cinco dias após a inoculação, para os isolados testados. Os mais patogênicos foram o IBCB-384, IBCB-348, ESALQ 1285, IBCB-345, ESALQ 319 e ESALQ 1037 que causaram mortalidades médias de 59,$7 ; 59,5 ; 57,9 ; 58,4 ; 53,9$ e
46,5\%, respectivamente (Figura 1). A variação da patogenicidade é observada com certa freqüência em bioensaios de seleção, podendo estar associada a fatores como baixa virulência do isolado, especificidade e tolerância do hospedeiro (ALVES, 1998). Diferenças na patogenicidade são indicativas de ocorrência natural de variação genética. Essa variação tem sido identificada em outros caracteres além da patogenicidade que incluem a dimensão dos conídios, taxas de crescimento e atividades enzimáticas (ST. LEGER et al., 1992).

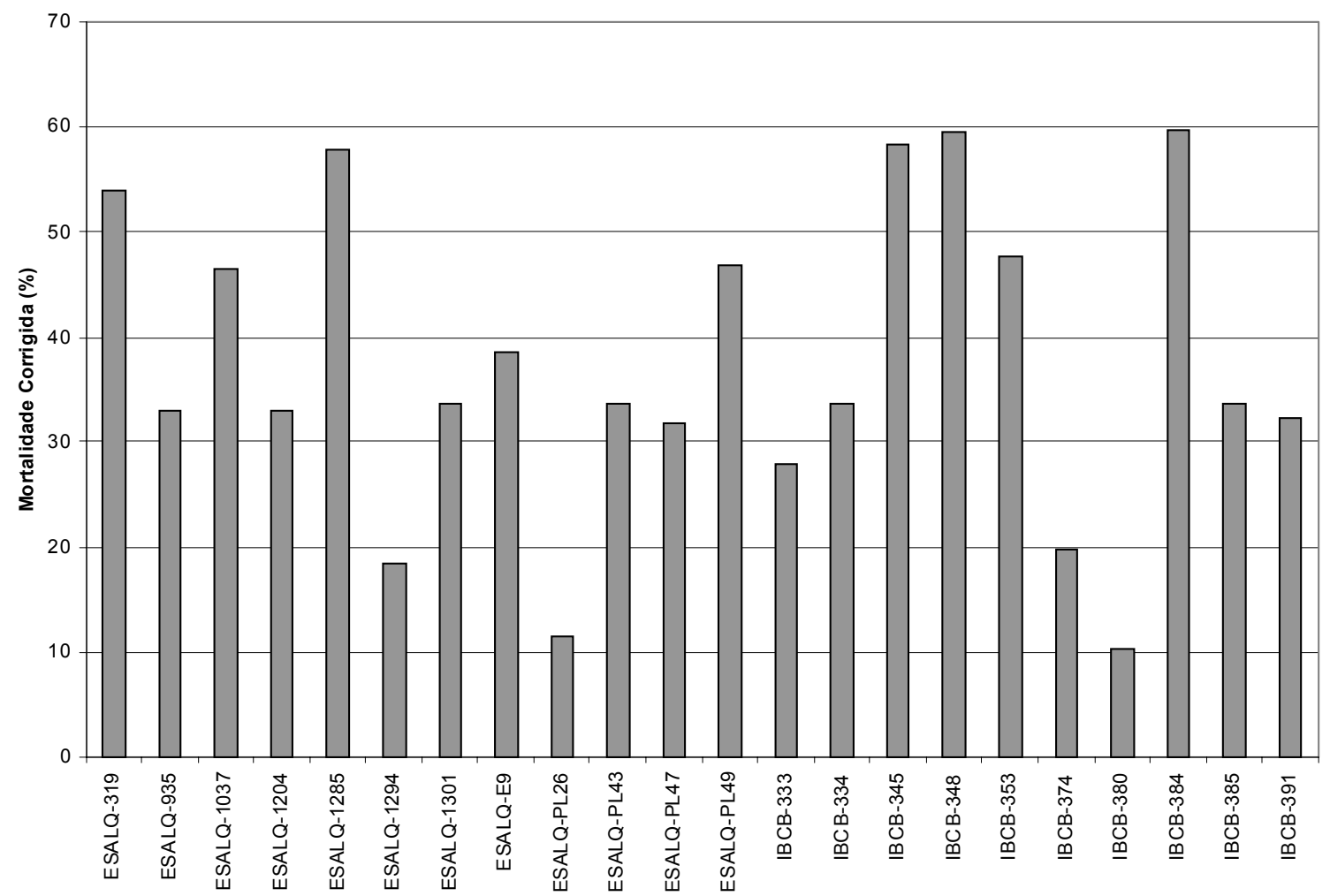

Figura 1. Mortalidades corrigidas (\%) causada pelos diferentes isolados de Metarhizium anisopliae em Mahanarva fimbriolata

A virulência e especificidade ao hospedeiro são duas características importantes para a seleção de um microrganismo a ser usado no controle microbiano (DEVI et al., 2001). Diferentes isolados preservados durante uma epizootia, numa mesma área e em uma mesma espécie de inseto hospedeiro mostram diferenças quanto à agressividade nesta mesma espécie de inseto quando testados em laboratório (BERRETTA et al., 1998). No presente trabalho evidenciou-se esse fato, uma vez que a maioria dos isolados testados é proveniente de uma mesma espécie de inseto e apresentaram diferentes graus de patogenicidade além de diferenças na morfologia das colônias e na esporulação.

A maioria dos trabalhos de seleção de isolados não correlaciona a patogenicidade e virulência de um determinado isolado ao seu local de origem ou hospedeiro, podendo esse material causar altos níveis 
de mortalidade a uma ampla gama de hospedeiros como foi observada para cupim de montículo em pastagens, pragas de grãos armazenados e larvas de escarabeídeos que atacam a cana-de-açúcar, cigarrinha das folhas (Mahanarva posticata) em cana-de-açúcar, cigarrinhas das pastagens (Deois flavopicta e Zulia entreriana) entre outros (FERNANDES; ALVES, 1991; MILNER, 1992; TIGANO-MILANI; GOMES; SOBRAL, 1995; ALMEIDA; ALVES; PEREIRA, 1997; MOINO JÚNIOR; ALVES; PEREIRA, 1998).

Alguns pesquisadores acreditam que a especialização ao hospedeiro não pode ser considerada como critério taxonômico, pois $M$. anisopliae é um patógeno facultativo o qual não está estritamente ligado a seu hospedeiro original (YIP; RATH; KOEN, 1992) e sua virulência e patogenicidade podem ser o resultado de um conjunto de enzimas atuando juntas (VARGAS et al., 2003).

Os resultados obtidos evidenciam a importância de efetuar bioensaios para a seleção de isolados antes do desenvolvimento de um produto microbiano. Esses bioensaios devem avaliar também a virulência das raças e dos patógenos visando selecionar, os que apresentem maior virulência, patogenicidade e que possam ser produzidos em meios artificiais (ALVES, 1998).

Inicialmente foram feitos testes preliminares, fornecendo folhas de cana-de-açúcar como alimento para as ninfas, obtendo-se na testemunha mortalidade acima de $50 \%$, quatro dias após a inoculação. O mesmo foi observado por Loureiro et al. (2005) quando utilizaram esta metodologia, os quais obtiveram mortalidades de até $90 \%$ na testemunha, seis dias após a inoculação.Com a mudança do método de bioensaio utilizado, fornecendo raízes de mudas de cana-de-açúcar como substrato para as ninfas, a mortalidade da testemunha, aos cinco dias após a inoculação foi inferior a $20 \%$. Isso se deve, provavelmente, ao alimento das ninfas, que no campo, é a seiva das raízes. Ao final das avaliações as mudas de cana mostravam-se com sintomas severos de ataque da praga, comprovando que as ninfas alimentaram-se das plantas.

A mortalidade pelo fungo pôde ser confirmada pelo exame das ninfas e adultos contaminados que foram mantidos em câmara úmida após a morte. Houve a completa colonização do fungo e sua posterior esporulação. Observou-se também que algumas ninfas não sofreram ecdise, uma vez que foram colonizadas pelo fungo.

De acordo com os resultados obtidos pode-se concluir que o fungo $M$. anisopliae é patogênico para ninfas de $M$. fimbriolata; os isolados de $M$. anisopliae apresentam diferentes níveis de patogenicidade para M. fimbriolata; e o método de bioensaio utilizado, fornecendo seiva de raiz de canade-açúcar como alimento, é eficiente para testes de patogenicidade.

\section{Referências}

ALMEIDA, J. E. M.; ALVES, S. B.; PEREIRA, R. M. Selection of Beauveria spp. isolates for control of the termite Heterotermes tenuis (Hagen, 1858). Journal of Applied Entomology, Berlin, v.121, n.9/10, p.538-543, 1997.

ALVES, S. B. Fungos entomopatogênicos. In: ALVES, S. B. (Ed.). Controle microbiano de insetos. Piracicaba: Fealq, 1998. cap.11, p.289-382.

AZZI, G. M.; DODSON, A. K. Infestação de cigarrinhada-raiz em canaviais de Piracicaba-SP (Mahanarva fimbriolata Stal). Brasil Açucareiro, Rio De Janeiro, n.5, p.36-42, 1971.

BERRETTA, M. F.; LECUONA, R. E.; ZANDOMENI, R. O.; GRAU, O. Genotyping isolates of the entomopathogenic fungus Beauveria bassiana by RAPD with fluorescent labels. Journal of Invertebrate Pathology, San Diego, v.71, n.2, p.145-150, 1998.

DEVI, K. U.; PADMAVATHI, J.; SHARMA, H. C.; SEETHARAMA, N. Laboratory evaluation of the virulence of Beauveria bassiana isolates to the sorghum shoot borer Chilo partellus Swinhoe (Lepidoptera: Pyralidae) and their characterization by RAPD-PCR. World Journal of Microbiology \& Biotechnology, Oxford, v.17, n.2, p.131-137, 2001.

DINARDO-MIRANDA, L. L.; COELHO, A. L.; FERREIRA, J. M. G. Influência da época de aplicação de inseticidas no controle de Mahanarva fimbriolata (Stal) (Hemiptera: 
Cercopidae), na qualidade e na produtividade da canade-açúcar. Neotropical Entomology, Londrina, v.33, n.1, p.91-98, 2004.

FERNANDES, P. M.; ALVES, S. B. Controle de Cornitermes cumulans (Kollar, 1832) (Isoptera: Termitidae) com Beauveria bassiana (Bals.) Vuill.; e Metarhizium anisopliae (Metsch.) Sorok. em condições de campo. Anais da Sociedade Entomológica do Brasil, Jaboticabal, v.20, p.45-49, 1991.

FREIRE, A. M.; SOUTO, C.E.R.; MARQUES, E. J.Combate biológico das cigarrinhas da cana-de-açúcar. Brasil Açucareiro, Rio De Janeiro, v.71, n.4, p.41-44, 1968.

LOUREIRO, E. S.; BATISTA FILHO, A.; ALMEIDA, J. E. M.; PESSOA, L. G. A. Seleção de isolados de Metarhizium anisopliae (Metch.) Sorok. Contra a cigarrinha da raiz da cana-de-açúcar Mahanarva fimbriolata (Stal) (Hemíptera: Cercopidae) em laboratório. Neotropical Entomology, Londrina, v.34, n.5, p.791-798, 2005.

MACEDO, N.; CAMPOS, M. B. S.; ARAÚJO, J. R. Insetos nas raízes e colo da planta, perfilhamento e produtividade em canaviais colhidos com e sem queima. STAB - Açúcar, Álcool e Subprodutos, Piracicaba, v.15, n.3, p.18-21, 1997.

MACEDO, N.; MACEDO, D. As pragas de maior incidência nos canaviais e seus controles. Visão Agrícola, Piracicaba, v.1, p.38-46, 2004.

MACEDO, N.; MENDES, A. C.; BOTELHO, P. S. M.; MAGRO, J. A. Metarhizium anisopliae (Metch) Sorokin no controle da cigarrinha da raiz (Mahanarva fimbriolata Stal) na cultura da cana-de-açúcar. Brasil Açucareiro, Rio De Janeiro, v.2, p.16-19, Ago. 1977.

MENDONÇA, A. F.; BARBOSA, G. V. S.; MARQUES, E. J. As cigarrinhas da cana-de-açúcar (Hemiptera: Cercopidae) no Brasil. In: MENDONÇA, A. F. (Ed.). Pragas da canade-açúcar. Maceió: Insetos \& CIA, 1996. p.171-192.
MILNER, R. J. The selection of strains of Metarhizium anisopliae for control of australian sugar-cane white grubs. In: GLARE, T. R.; JACKSON, T. A. (Ed.). Use of pathogens in scarab pest management. England: Athenacum Press, 1992.

MOINO JÚNIOR, A.; ALVES, S. B.; PEREIRA, R. M. Efficacy of Beauveria bassiana (Balsamo) Vuillemin isolates for control of stored-grain pests. Journal of Applied Entomology, Berlin, v.122, p.301-305, 1998.

SOSA-GÓMEZ, D. R.; PEREIRA, R. M.; ALVES, S. B. Impacto ambiental de entomopatógenos. In: ALVES, S. B. (Ed.). Controle microbiano de insetos. Piracicaba: Fealq, 1998. cap.37, p.1075-1095.

St. LEGER, L. J.; MAY, B.; ALLEE, L. L.; FRANK, D. C.; STAPLES, R. C.; ROBERTS, D. W. Genetic differences in allozymes and in formation of infection structures among isolates of the entomopathogenic fungus Metarhizium anisopliae. Journal of Invertebrate Pathology, San Diego, v.60, p.89-101, 1992.

TIGANO-MILANI, M. S.; GOMES, A. C. M. M.; SOBRAL, B. W. S. Genetic variability among Brazilian isolates of the entomopathogenic fungus Metarhizium anisopliae. Journal of Invertebrate Pathology, San Diego, v.65, p.206210, 1995.

VARGAS, L. R. B.; ROSSATO, M.; RIBEIRO, R. T. S.; BARROS, N. M. Characterization of Nomuraea rileyi strains using polymorphic DNA, virulence and enzyme activity. Brazilian Archives of Biology and Technology, Curitiba, v.46, n.1, p.13-18, Jan. 2003.

YIP, H. Y.; RATH, A. C.; KOEN, T. B. Characterization of Metarhizium anisopliae isolates from Tasmanian pasture soils and their pathogenicity to redheaded cockchafer (Coleoptera: Scarabeidae: Adoryphorus couloni). Mycological Research, Cambridge, v.96, n.2, p.92-96, 1992. 